\title{
Simultaneous Free Convection and Heat Generation on a Horizontal Isothermal Circular Cylinder
}

\author{
Sajjad Sedighi ${ }^{1} \&$ Mohammad Saeed Aghighi $^{1}$ \\ ${ }^{1}$ Bu-Ali Sina University, Hamedan, Iran \\ Correspondence: Sajjad Sedighi, Tavoos Alley, Parastoo St, Motekhassesin quarter, Hamedan, Iran. Tel: \\ 98-935-352-9952. E-mail: direct2.2006@gmail.com
}

Received: April 20, 2015

Accepted: June 11, 2015

Online Published: October 31, 2015

doi:10.5539/mas.v9n12p21

URL: http://dx.doi.org/10.5539/mas.v9n12p21

\begin{abstract}
The linear boundary layer of the free flow around a circular horizontal cylinder with uniform surface temperature in the presence of heat generation was studied. Upon obtaining the non-dimensional boundary layer equations, the Runge-Kutta series method was used to solve the non-linear partial differential equations numerically. The surface shear stress results and surface heat rate were subsequently obtained in terms of the internal shell friction and the local Nusselt number respectively. The following heat generation parameters $(\mathrm{C})$ were selected: 0.0 , $0.2,0.5,0.8$, and 1.0. The following results were obtained: 1 ) increasing $\mathrm{C}$ led to a corresponding increase $\mathrm{u}, \mathrm{v}$, $\mathrm{VM}$, and $\theta, 2$ ) Increasing $i$ led to a corresponding increase in $\mathrm{u}, \mathrm{v}$, and $\mathrm{VM}$, and 3) increasing $\mathrm{C}$ increased velocity variations and, naturally, the value of $\mathrm{Cf}$, and 4 ) increasing $\mathrm{i}$ from $\mathrm{i}=0$ to $\mathrm{i}=100$ led to a decrease in the Nusselt number $(\mathrm{Nu})$.
\end{abstract}

Keywords: heat transfer, free convection, horizontal cylinder, numerical solution

\section{Nomenclature}

a radius of the circular cylinder

Cf local skin-friction coefficient

Cp specific heat at constant pressure

$f \quad$ dimensionless stream function

Gr Grashof number

$g \quad$ acceleration due to gravity

$k \quad$ thermal conductivity

$\mathrm{Nu}$ local Nusselt number

Pr Prandtl number

$Q_{0} \quad$ constant

$q_{w} \quad$ heat flux at the surface

$T$ temperature of the fluid in the boundary layer

$T_{\infty} \quad$ temperature of the ambient fluid

$T_{w} \quad$ temperature at the surface

$U_{\infty} \quad$ dimensionless free stream velocity

$u, v \quad$ dimensionless velocity components along $x$ and $y$-directions

$\hat{u}, \hat{v} \quad$ Fluid velocities in the $x^{\wedge}$ and $y^{\wedge}$ directions

$x, y \quad$ axis in the direction along and normal to the surface respectively

Greek symbols

$\psi \quad$ stream function

$\tau_{w} \quad$ shearing stress 
$\rho$

$\mu \quad$ viscosity of the fluid

$v \quad$ kinematic viscosity

$\gamma \quad$ heat generation parameter

$\theta$ dimensionless temperature function

$\beta \quad$ coefficient of thermal expansion

Subscripts

w wall conditions

$\infty \quad$ ambient temperature

Superscript

differentiation with respect to $y$

\section{Introduction}

Free convection heat transfer occurs as a result of the change in density resulting from slight differences in temperature between fluid components, which create buoyancy forces in the fluid. Therefore, any change in the existing temperature difference would introduce instabilities in the heat transfer flow.

Due to the significance and frequent occurrence in nature of free convection flow, this form of heat transfer has long been the subject of numerous studies (Takhar 1968; Merkin 1969; Sparrow, Husar, and Goldestein 1969; Corcione 2005; Molla, Hossein, and Paul 2006).

The convective heat transfer can be classified in terms of the nature of the flow. "Forced convection" is caused via external sources such as fans, pumps, and atmospheric winds. An example of forced convection is the cooling of hot electrical components on integrated circuit boards through forced convection provided by a fan. On the other hand, "free (natural) convection" is created via forces of buoyancy resulting from differences in density caused by temperature difference between adjacent fluid layers. An example of free convection can be observed in the heat transfer from the hot components in the vertical arrays of integrated circuit boards in stagnant air. The temperature of the air in contact with the hot surfaces increases, resulting in a decrease in its density. As hot air is lighter than the ambient air, buoyancy forces are created, resulting in an upward motion of the hot air and its consequent replacement with cold air.

Wageravelo and Hodgincolova (Vajravelu, Hadjinicolaou 1993) studied the heat transfer characteristics of the linear boundary layer flow of a viscous fluid on a linearly expanded continuous surface in the presence of viscous friction heat loss and internal heat generation. They observed that the volumetric heat transfer rate $\phi\left[\frac{h}{m^{3}}\right]$ was obtained from the relation 1 :

$$
\phi= \begin{cases}Q_{0}\left(T-T_{\infty}\right) & \text { for } T \geq T_{\infty} \\ 0 & \text { for } T<T_{\infty}\end{cases}
$$

Where $\mathrm{Q}_{0}$ is the steady state heat transfer rate and $\mathrm{T}_{\infty}$ is ambient temperature. The above relation is used for some of the exothermic process that begins when the temperature $\mathrm{T}$ is existent.

On the other hand, many physical phenomena involve convective heat transfer resulting from heat generation. Heat generation study is also important where moving fluids are concerned in spite of numerous physical difficulties that exist including chemical reactions resulting in decomposition of the fluid.

The rate of free convection heat transfer is much less than that of forced convection due to the higher velocities involved in the latter. Perhaps less importance is generally attaché to processes which include free convection. However, free convection plays a significant role in the design and performance of hybrid heat transfer systems because of the high resistance to heat transfer associated with it (Incropera, Dewett, Bergman, and Lavine 2002).

The effect of heat generation and absorption on magnetic water flow on a plate in the presence of heat and mass transfer was studied by Chamkha and Isa (2000). Mendez and Trevino (2000) also studied the combined effects of conductivity and natural convection along a thin vertical sheet in the presence of non-uniform heat generation. Molla, Hossein, and Yao (2004) studied the natural convective flow in the presence of heat generation along a warped uniformly heated vertical surface. 
In 1976, Sparrow and Lee investigated the problem of simultaneous convection on a heated horizontal circular cylinder. They developed a solution for velocity and temperature profiles in the $\mathrm{x}$ direction corresponding to the lowest point on the cylinder. Merkin $(1976,1977)$ was the first author to present a complete solution to this problem by combining the Blasius-Gurlter series expansions with an integration method and a finite difference program. Merkin (1977) also studied the problem of boundary layer free convection from elliptical cylinders. Later, Ingham (1978) studied the boundary layer free convection flow on an isothermal horizontal cylinder. Hossain and Alim (1997) also investigated the mutual effect of radiation on natural convection boundary layer flow along a thin vertical cylinder. Hossein and Kutubuddin (1999) conducted studies on the effect of radiation-conductivity on the mixed convection flow on a horizontal circular cylinder. Later, Molla, Hossain, and Gorla (2005) studied the natural convection flow around a horizontal circular isothermal cylinder where the temperature was dependent on viscosity.

There are also several articles published in various journals on micro magnetic flux applications. For example, Pop, Nazar, and Amin (2002), studied the problem of natural convection flow from a lower to a higher stagnation point on a horizontal circular cylinder submerged in a micro magnetic flux. Subsequently, Pop, Nazar, and Amin (2002) investigated the natural convection flow on an isothermal sphere inside a fluid. In several other studies, the natural boundary layer flow on a sphere was investigated. For example, Chiang, Ossin, and Tien (1964) studied the free linear convection flow on a sphere by taking into account surface temperature and thermal flux. In 1987, Huang and Chen studied the natural convection flow on a sphere caused by blowing and suction. Simultaneous analysis of free and forced convections around a sphere was conducted by Chen and Mocoglu (1977). Molla, Hossain, and Gorla (2004) studied heat and mass transfer from a sphere as a result of chemical reactions.

In the present study, the linear boundary layer in free convection from a horizontal circular cylinder at uniform surface temperature in the presence of heat generation was investigated. First, the non-dimensional boundary layer equations were obtained, and then the system of partial differential equations were numerically solved via the Runge-Kutta series technique (Butcher 1974). The results of shear stress and the surface heat rate were obtained in terms of the internal shell friction and the local Nusselt number respectively for the selected values of the heat generation parameter $(C=0.0,0.2,0.5,0.8$, and 1.0$)$. Results are presented in diagrams.

\subsection{Dominant Equations}

Figure 1 shows the heated cylinder. A steady linear 2D free convection flow is established on the surface of a circular horizontal isothermal cylinder with radius $a$, submerged in a viscous incompressible fluid. $\mathrm{T}_{\mathrm{w}}$ is the surface temperature of the cylinder $\left(T_{w}>T_{\infty}\right) . T_{\infty}$ represents the fluid ambient temperature, and $\mathrm{T}$ is the fluid temperature. The 2D physical representation of the cylinder is shown in the Figure 1.

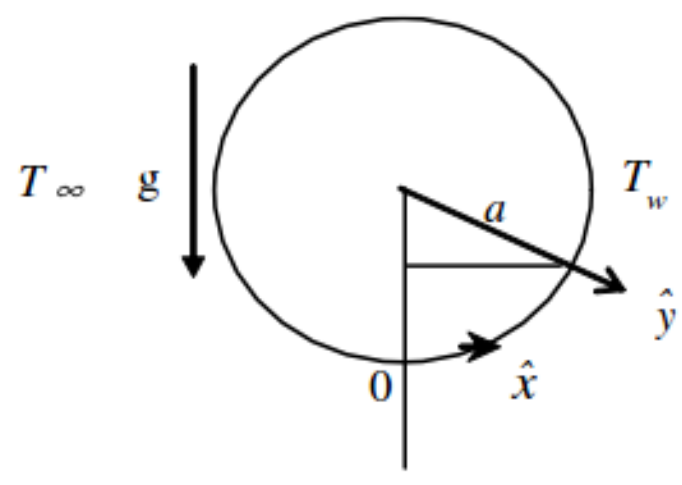

Figure 1. The physical model and the assumed coordinates

Relations 2 to 4 are obtained upon applying the boundary layer and Boussinesq approximations to the continuous mass, momentum, and energy equations respectively(Molla, Hossein, and Paul , 2006) :

$$
\frac{\partial \hat{u}}{\partial \hat{x}}+\frac{\partial \hat{v}}{\partial \hat{y}}=0
$$




$$
\begin{array}{r}
\rho\left(\hat{u} \frac{\partial \hat{u}}{\partial \hat{x}}+\hat{v} \frac{\partial \hat{u}}{\partial \hat{y}}\right)=\mu \frac{\partial^{2} \hat{u}}{\partial \hat{y}^{2}}+\rho g \beta\left(T-T_{\infty}\right) \sin \left(\frac{\hat{x}}{a}\right) \\
\hat{u} \frac{\partial T}{\partial \hat{x}}+\hat{v} \frac{\partial T}{\partial \hat{y}}=\frac{k}{\rho C_{p}} \frac{\partial^{2} T}{\partial \hat{y}^{2}}+\frac{Q_{o}}{\rho C_{p}}\left(T-T_{\infty}\right)
\end{array}
$$

Where $(\mathrm{u}, \mathrm{v})$ are velocity components in the $(\mathrm{x}, \mathrm{y})$ directions, $\mathrm{g}$ is the acceleration of gravity, $\rho$ is fluid density, $\mathrm{k}$ is thermal conductivity, $\mu$ is fluid viscosity, $\mathrm{Cp}$ is specific heat at constant pressure, and $\mathrm{Q}_{0}$ is constant (positive or negative) heat generation. $\mathrm{Q}_{0}>0$ and $\mathrm{Q}_{0}<0$ correspond to heat generation and heat absorption respectively.

The proper boundary conditions for solving equations 2 to 4 are:

$$
\begin{gathered}
\hat{u}=\hat{v}=0, T=T_{w} \quad \text { at } \hat{y}=0 \\
\hat{u} \rightarrow, T \rightarrow T_{\infty} \text { as } \hat{y} \rightarrow \infty
\end{gathered}
$$

Upon obtaining the non-dimensional forms of equations 2 to 4 and substituting the non-dimensional variables, we obtain:

$$
\begin{aligned}
x & =\frac{\hat{x}}{a}, \quad y=G r^{1 / 4}\left(\frac{\hat{y}}{a}\right) \\
u & =\frac{a}{v} G r^{-1 / 2} \hat{u}, \quad v=\frac{a}{v} G r^{1 / 4} \hat{v} \\
\theta & =\frac{T-T_{\infty}}{T_{w}-T_{\infty}}, G r=g \beta\left(T_{w}-T_{\infty}\right) \frac{a^{3}}{v^{2}}
\end{aligned}
$$

Finally, by substituting Equations 6, 7, and 8 into Equations 2, 3, and 4 respectively, we obtain:

$$
\begin{gathered}
\frac{\partial u}{\partial x}+\frac{\partial v}{\partial y}=0 \\
u \frac{\partial u}{\partial x}+v \frac{\partial u}{\partial y}=\frac{\partial^{2} u}{\partial y^{2}}+\theta \sin x \\
u \frac{\partial \theta}{\partial x}+v \frac{\partial \theta}{\partial y}=\frac{1}{\operatorname{Pr}} \frac{\partial^{2} \theta}{\partial y^{2}}+\frac{Q_{0} a^{2}}{\mu C_{p} G r^{1 / 2}} \theta
\end{gathered}
$$

The boundary conditions are:

$$
\begin{aligned}
& u=v=0, \theta=1 \text { at } y=0 \\
& u \rightarrow 0, \theta \rightarrow 0 \text { as } y \rightarrow \infty
\end{aligned}
$$

$\mathrm{C}$ in Equation 11 is defined as:

$$
C=\frac{Q_{0} a^{2}}{\mu C_{p} G r^{1 / 2}}
$$

Substitution of equation 13 into 11 results in the relation 14 :

$$
u \frac{\partial \theta}{\partial x}+v \frac{\partial \theta}{\partial y}=\frac{1}{\operatorname{Pr}} \frac{\partial^{2} \theta}{\partial y^{2}}+C \theta
$$

We shall try to obtain $\mathrm{v}, \mathrm{u}$, and $\theta$ from Equations 9, 10, and 14 respectively. To this end, we obtain $\frac{\partial u}{\partial x}$ from the conservation of mass equation (Equation 9) and replace it in Equation 10. Subsequently, we solve this system of equations simultaneously to obtain:

$$
\frac{\partial u}{\partial x}=-\frac{\partial v}{\partial y} \quad \rightarrow \frac{\partial u}{\partial x}+\frac{\partial v}{\partial y}=0
$$


Substitution of equation 15 in 10 results in the following relations:

$$
\begin{gathered}
\frac{\partial u}{\partial t}-u \frac{\partial v}{\partial y}+v \frac{\partial u}{\partial y}=\frac{\partial^{2} u}{\partial y^{2}}+\theta^{*} \operatorname{Sin}(x) \\
\frac{\partial \theta}{\partial t}+u \frac{\partial \theta}{\partial x}+v \frac{\partial \theta}{\partial y}=\frac{1}{\operatorname{Pr}} \frac{\partial^{2} \theta}{\partial y^{2}}+\theta^{*} C
\end{gathered}
$$

On the other hand, the required physical quantities, i.e., shear stress and heat transfer rate (expressed in terms of surface friction coefficient, $\mathrm{Cf}$, and the Nusselt number, $\mathrm{Nu}$ ) can be written as:

$$
C_{f} \equiv \frac{\tau_{s}}{\rho u_{\infty}^{2} / 2}
$$

Where:

$$
\begin{gathered}
N u \equiv \frac{h L}{k_{f}} \\
\tau_{s}=\left.\mu \frac{\partial u}{\partial y}\right|_{y=0} \\
h=\frac{-k_{f} \partial T /\left.\partial y\right|_{y=0}}{T_{s}-T_{\infty}} \rightarrow \quad q_{s}^{\prime \prime}=-\left.k_{f} \frac{\partial T}{\partial y}\right|_{y=0}
\end{gathered}
$$

Where $\tau_{s}$ is the shearing stress, $q^{\prime \prime}$ is the local thermal flux, $h$ is the local convection coefficient, $\rho$ is the fluid density, $\mathrm{k}$ is thermal conductivity, $\mu$ is the fluid viscosity, $L$ is length scale, $T_{s}$ is the surface temperature, and is the ambient temperature.

\section{Results}

The variations in the $\mathrm{u}$ and $\mathrm{v}$ velocities and in temperature were studied. The variations in $\mathrm{Nu}$ and $\mathrm{Cf}$ were also investigated. The problem was solved considering $\operatorname{Pr}=0.7[1], \mathrm{dx}=0.01$, and $\mathrm{dy}=0.01$. The accuracy of $\mathrm{dt}$ was assumed as 0.00001 . According to Figure 1, and by solving equations (9), (10), and (14), the variations in velocity and temperature was obtained by changing the parameter $\mathrm{C}$ from 0 to 1 and assuming a constant $\mathrm{x}$ at $\mathrm{i}=0$, 50, and 100. These variations are shown in the Figures 2 to 7 .

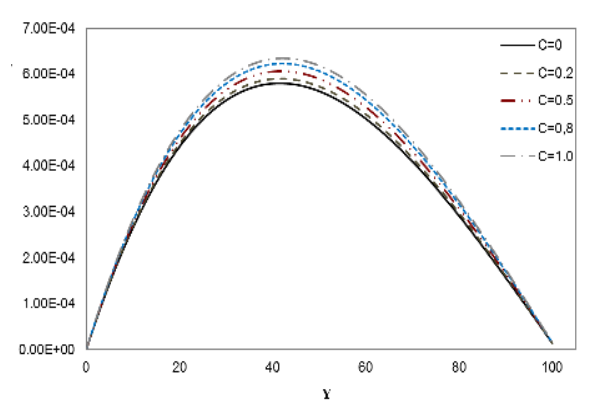

Figure 2(a). Variations in the velocity of $\mathrm{u}$ in the $\mathrm{x}$-direction at $\mathrm{I}=0$ at different values of C.TIF

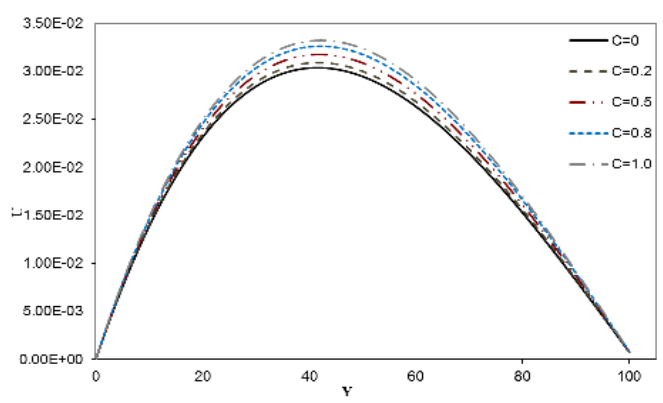

Figure 2(b). Variations in the velocity of $\mathrm{u}$ in the $\mathrm{x}$-direction at $\mathrm{I}=50$ at different values of $\mathrm{C}$ 


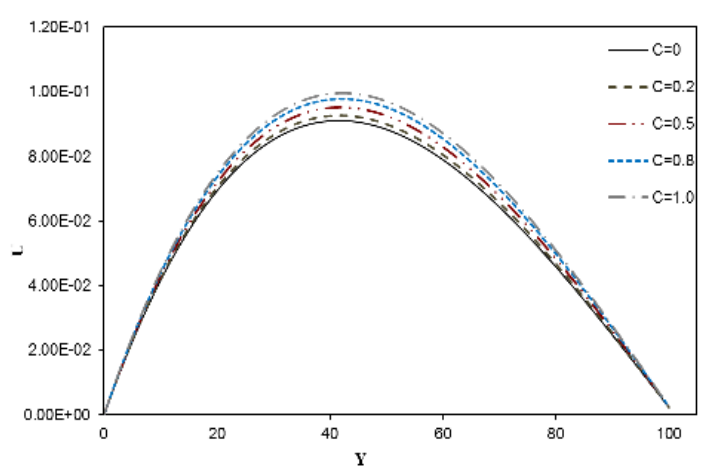

Figure 2(c). Variations in the velocity of $\mathrm{u}$ in the $\mathrm{x}$-direction at $\mathrm{I}=100$ at different values of $\mathrm{C}$.

As seen in Figure 2, increase in $\mathrm{C}$ increased the magnitude of $\mathrm{u}$. This is due to a direct dependence of the parameter $C$ to $\mathrm{Q}_{0}$ as indicated in equation (13). Equation (13) implies that increase in $\mathrm{Q}_{0}$ increases the parameter C. It can be said that increase in $\mathrm{Q}_{0}$ increased the $u$ velocity which is justifiable and shown in Figure 2(a), 2(b), 2(c).

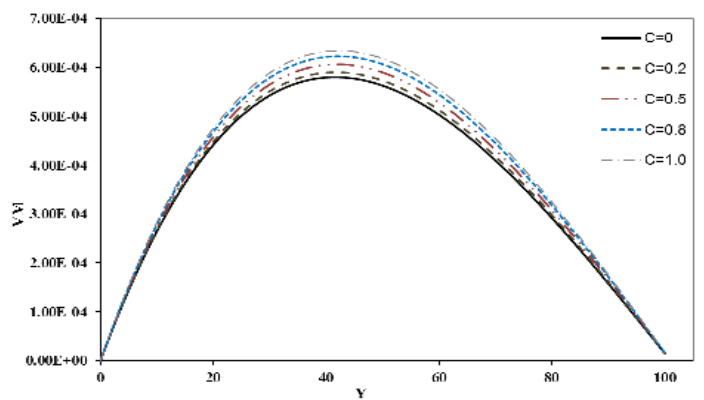

Figure 3(a). Variations in the velocity of $\mathrm{v}$ in the $\mathrm{x}$-direction at $\mathrm{I}=0$ at different values of $\mathrm{C}$

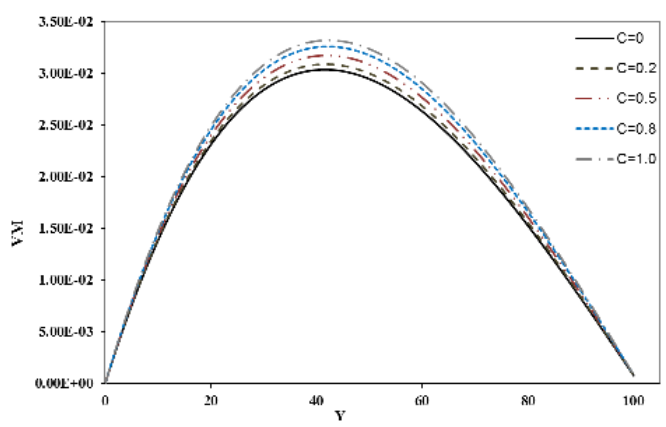

Figure $3(\mathrm{~b})$. Variations in the velocity of $\mathrm{v}$ in the $\mathrm{x}$-direction at $\mathrm{I}=50$ at different values of $\mathrm{C}$

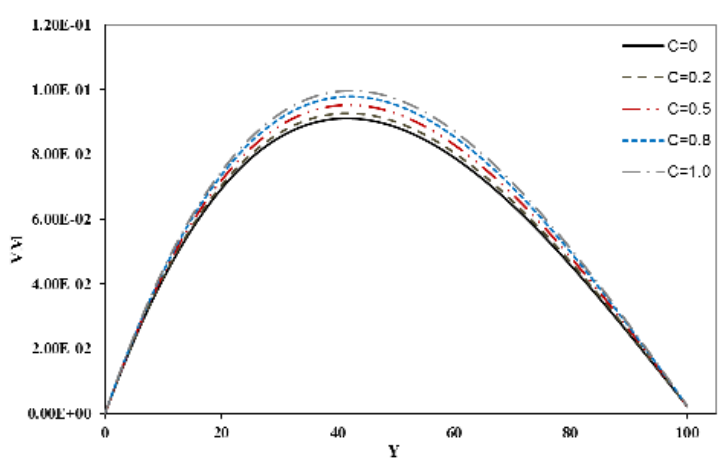

Figure 3(c). Variations in the velocity of $\mathrm{v}$ in the $\mathrm{x}$-direction at $\mathrm{I}=100$ at different values of $\mathrm{C}$ 
As shown in Figure 3(a), 3(b), 3(c), v increased as the parameter $\mathrm{C}$ increased, which is due to the direct dependence of the parameter $\mathrm{C}$ to the heat generation parameter, $\mathrm{Q} 0$. This is consistent with the obtained results.

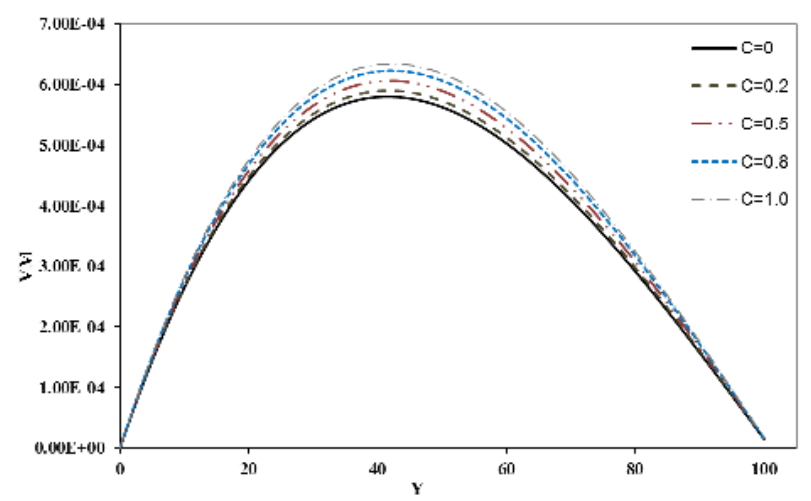

Figure 4(a). Variations in the absolute velocity of VM in the $\mathrm{x}$-direction at $\mathrm{I}=0$ at different values of $\mathrm{C}$

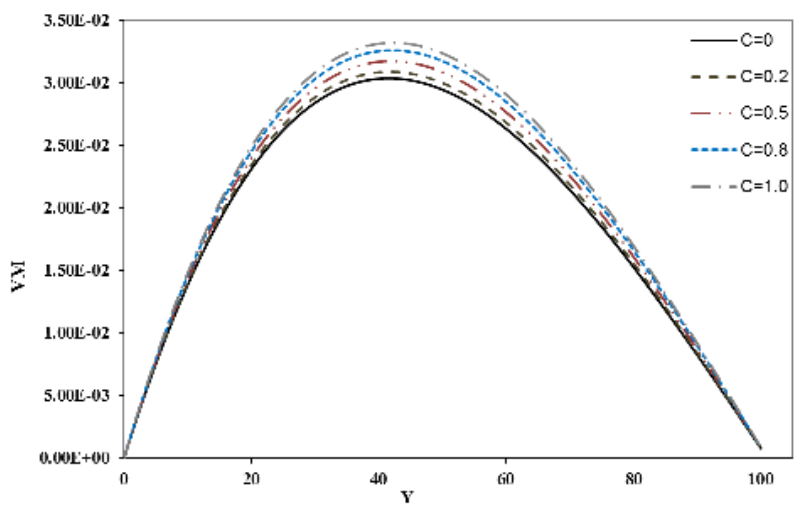

Figure 4(b). Variations in the absolute velocity of VM in the $\mathrm{x}$-direction at I $=50$ at different values of C

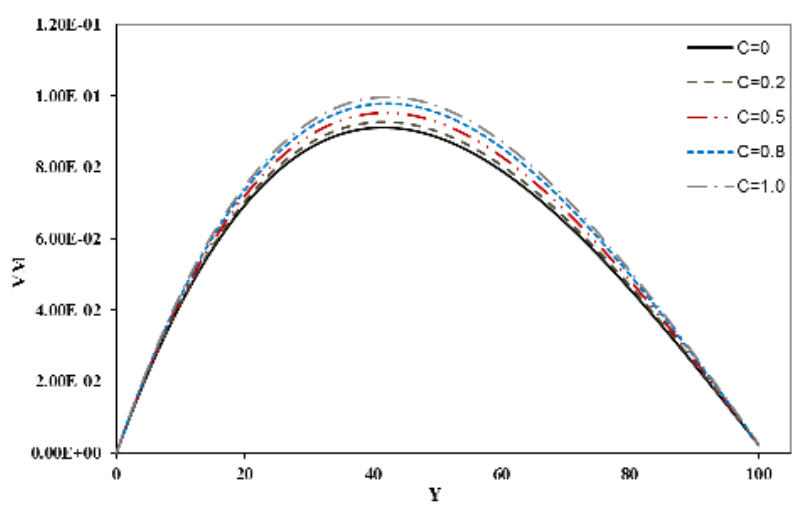

Figure 4(c). Variations in the absolute velocity of VM in the $\mathrm{x}$-direction at $\mathrm{I}=100$ at different values of C

Equation (6) defines the absolute velocity, VM, as the resultant of the magnitudes of the velocities $\mathrm{u}$ and $\mathrm{v}$. Therefore, according to the results presented in Figures 2 and 3, increase in $\mathrm{C}$ increased the magnitude of VM which is consistent with the obtained results (Figure 4(a), 4(b), 4(c)). 


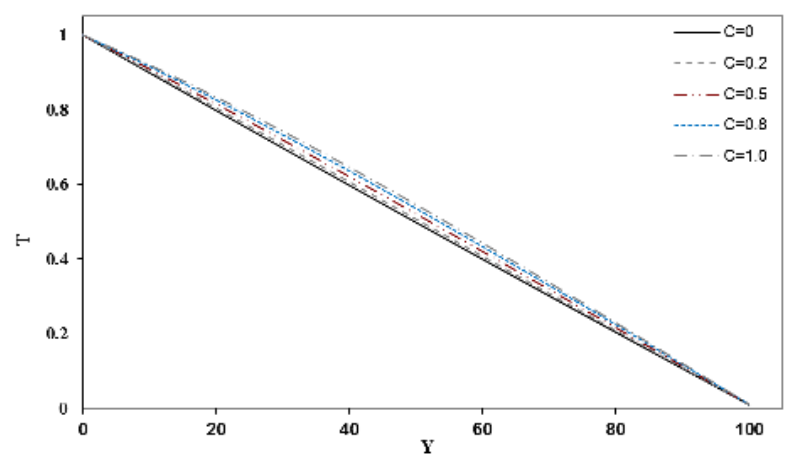

Figure 5(a). Variations in the velocity of $\mathrm{T}$ in the $\mathrm{y}$-direction at $\mathrm{I}=0$ at different values of $\mathrm{C}$

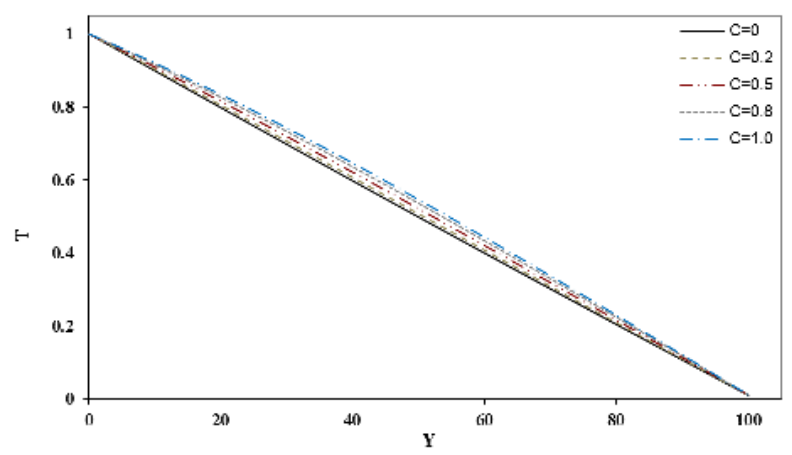

Figure 5(b). Variations in the velocity of $\mathrm{T}$ in the $\mathrm{y}$-direction at $\mathrm{I}=50$ at different values of $\mathrm{C}$

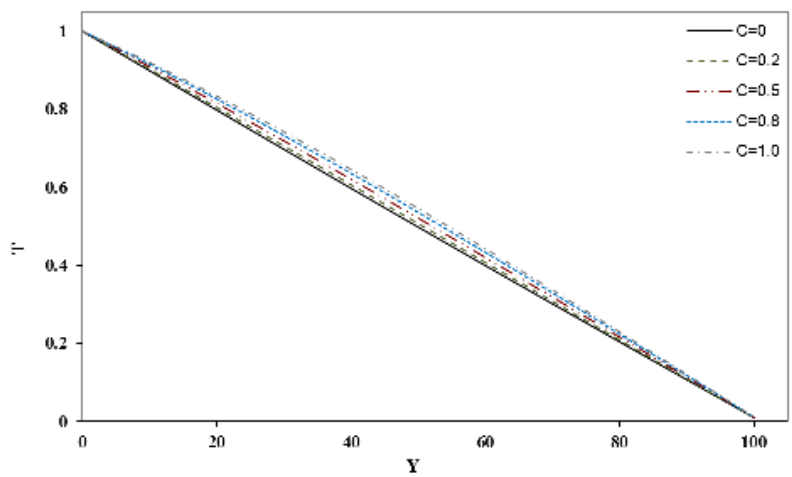

Figure 5(c). Variations in the velocity of $\mathrm{T}$ in the $\mathrm{y}$-direction at $\mathrm{I}=100$ at different values of $\mathrm{C}$

As seen in Figure 5(a), 5(b), 5(c), increase in the parameter $\mathrm{C}$ increased $\theta$, which is due to a direct dependence of the parameter $\mathrm{C}$ to the heat generation parameter, $\mathrm{Q} 0$, and is consistent with the obtained results.

It is evident that the maximum value of $\theta$ occurred at the body of the cylinder due to the highest difference between $\mathrm{T}$ and $T_{\infty}$. The minimum temperature (close to zero) was observed at the remote areas due to the closeness to $T_{\infty}$. 


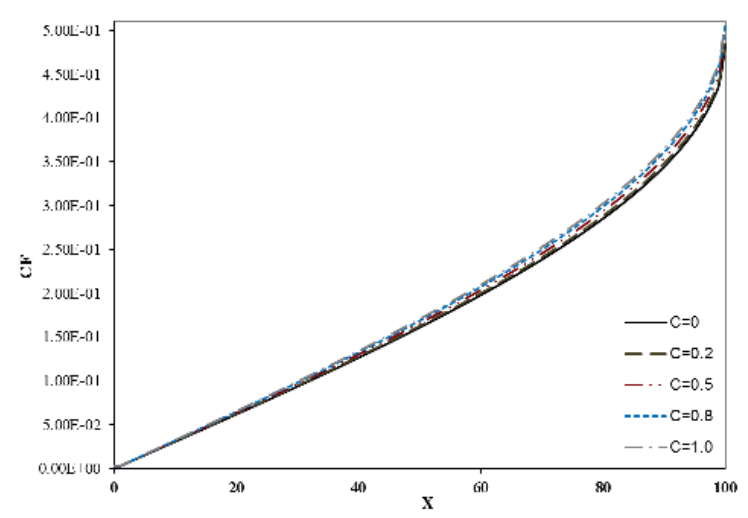

Figure 6. Variations in $\mathrm{Cf}$ at different values of $\mathrm{C}$

Equations (18) and (20) imply that $\mathrm{Cf}$ is a function of the y-direction velocity (i.e., radial velocity). By moving from $i=0$ towards $i=100$, the changes in velocity at $y=0$ increased due to the development of the boundary layer. The variations in velocity increased as the value of $\mathrm{C}$ increased, and consequently, $\mathrm{Cf}$ increases. The obtained data are in agreement with this matter (Figure 6).

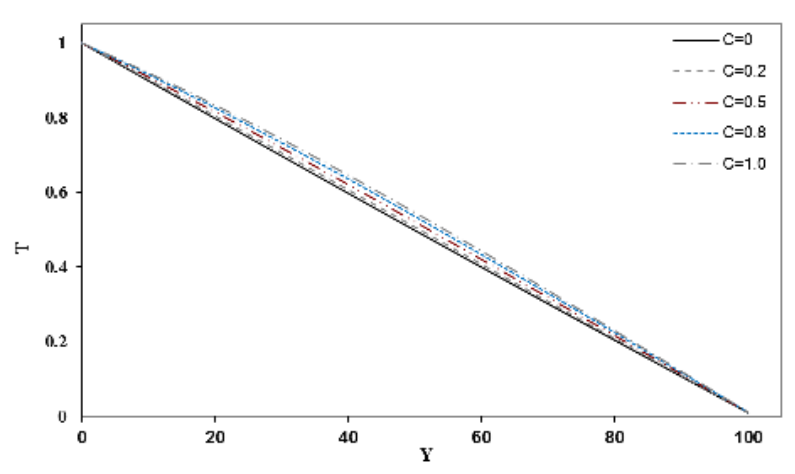

Figure 7(a). Variations in the velocity of $\mathrm{Nu}$ at $\mathrm{I}=0$ at different values of $\mathrm{C}$

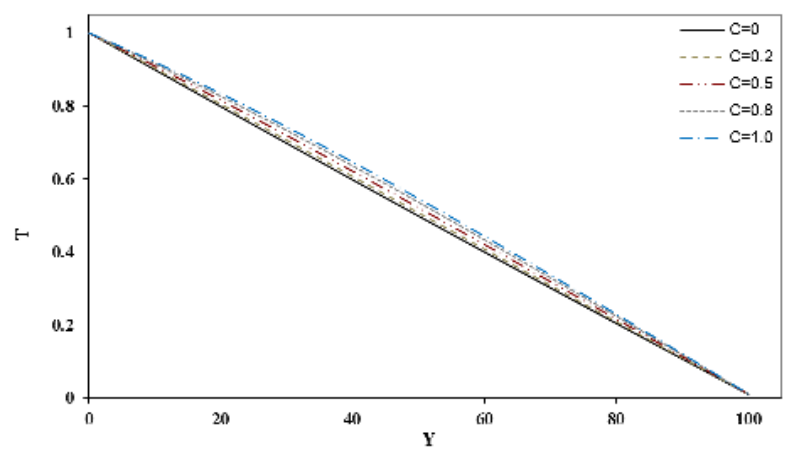

Figure 7(b). Variations in the velocity of $\mathrm{Nu}$ at $\mathrm{I}=50$ at different values of $\mathrm{C}$ 


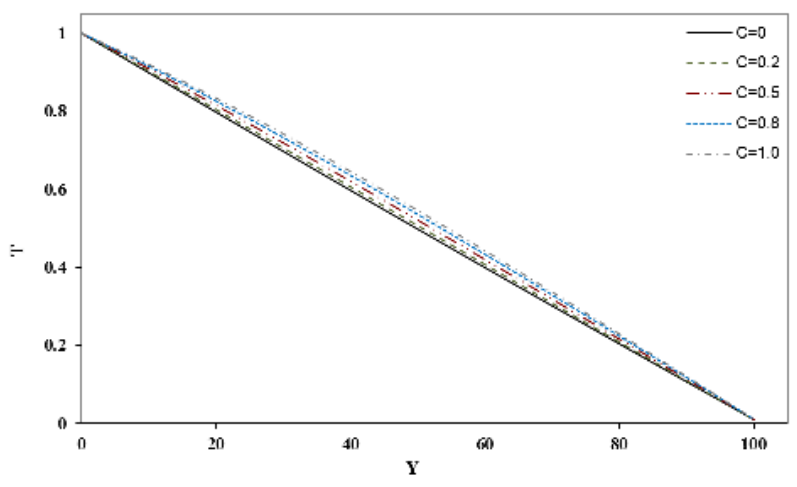

Figure 7(c). Variations in the velocity of $\mathrm{Nu}$ at $\mathrm{I}=100$ at different values of $\mathrm{C}$

The temperature variation gradient decreased with the development of the boundary layer. Therefore, by moving from $\mathrm{i}=0$ towards $\mathrm{i}=100, \mathrm{Nu}$ decreased according to the equations (19) and (21). Since the variations in $\mathrm{Nu}$ are very low, it is illustrated in a limited view in Figure 7(a), 7(b), 7(c). As seen in those Figures, decrease in C will decrease $\mathrm{Nu}$.

\section{Conclusion}

The effect of heat generation on the natural convection flow on an isothermal horizontal cylinder was numerically investigated. The boundary layer equations governing the motion were presented in the dimensionless form. The set of nonlinear results was simplified to the dissimilar boundary layer equations. The equations were solved numerically by the Runge-Kutta method. Results showed that increase in the parameter $\mathrm{C}$ led to an increase in $\mathrm{C}, \mathrm{u}, \mathrm{v}, \mathrm{VM}$, and $\theta$. Also, increase in i increased $\mathrm{u}, \mathrm{v}$, and VM. Increase in C led to an increase in the variation of velocity, and thereby, increased $\mathrm{Cf}$. The value of $\mathrm{Nu}$ decreased by moving from $\mathrm{i}=0$ towards $\mathrm{i}=100$.

\section{References}

Butcher, J. C. (1974). Implicit Runge-Kutta process. Mathematics of Computation, 18, 50-55.

Chamkha, A. J., \& Issa, C. (2000). Effects of heat generation/absorption and the thermophoresis on hydromagnetic flow with heat and mass transfer over a flat plate. International Journal of Numerical Methods for Heat \& Fluid Flow, 10(4), 432-448. http://dx.doi.org/10.1108/09615530010327404.

Chen, T. S., \& Mocoglu, A. (1977). Analysis of mixed forced and free convection about a sphere. International Journal of Heat Mass Transfer, 109(2), 529-532. http://dx.doi.org/867-875.10.1016/0017-9310(77)90116-8.

Chiang, T., Ossin, A., \& Tien, C. L. (1964). Laminar free convection from a sphere. ASME Journal of Heat Transfer, 86, 537-542. http://dx.doi.org/10.1115/1.3688739.

Corcione, M. (2005). Correlating equations for free convection heat transfer from horizontal isothermal cylinders set in a vertical array. International Journal of Heat Mass Transfer, 48, 3660-3673. http://dx.doi.org/10.1016/j.ijheatmasstransfer.2005.01.010.

Hossain, M. A., \& Alim, M. A. (1997). Natural convection-radiation interaction on boundary layer flow along a vertical thin cylinder. Heat and Mass Transfer, 32, 515-520. http://dx.doi.org/10.1007/s002310050153

Hossain, M. A., Kutubuddin, M., \& Pop, I. (1999). Radiation-conduction interaction on mixed convection a horizontal circular cylinder. Heat and Mass Transfer, 35, 307-314. http://dx.doi.org/10.1007/s002310050329

Huang, M. J., \& Chen, C. K. (1978). Laminar free convection from a sphere with blowing and suction. ASME Journal of Heat Transfer, 109, 529-532. http://dx.doi.org/10.1115/1.3248117

Incropera, F. P., Dewett, D. P., Bergman, T. L., \& Lavine A. S. (2002). Introduction to heat transfer (4th Ed.). Wiley, USA.

Ingham, D. B. (1978). Free convection boundary layer on an isothermal horizontal cylinder. Zeitschrift Fur Angewandte Mathematik und Physik, 29, 871-883. http://dx.doi.org/10.1007/BF01590813

Mendez, F., \& Trevino, C. (2000). The conjugate conduction-natural convection heat transfer along a thin vertical plate with non-uniform internal heat generation. International Journal of Heat and Mass Transfer, 


\section{3, 2739-2748. http://dx.doi.org/ 10.1016/S0017-9310(99)00331-2}

Merkin, J. H. (1969). The effect of buoyancy forces on The boundary-layer flow. Journal of fluid Mech., 35, 49-450. http://dx.doi.org/10.1017/S0022112069001212

Merkin, J. H. (1976). Free convection boundary layer on an isothermal horizontal circular cylinders, in: ASME/AIChE. Heat Transfer Conference, St. Louis, MO, 9-11.

Merkin, J. H. (1977). Free convection boundary layer on cylinders of elliptic cross-section. ASME Journal of Heat Transfer, 99, 453-457. http://dx.doi.org/10.1115/1.3450717

Merkin, J. H. (1977). Mixed convection a horizontal circular cylinder. International Journal of Heat Mass Transfer, 20, 73-77. http://dx.doi.org/10.1016/0017-9310(77)90086-2

Molla, M. M., Hossain, M. A., \& Gorla, P. S. R. (2005). Natural convection flow from an isothermal horizontal circular cylinder with temperature dependent viscosity. Heat and Mass Transfer, 41, 594-598. http://dx.doi.org/10.1007/s00231-004-0576-7

Molla, M. M., Hossain, M. A., \& Gorla, R. S. R. (2004). Conjugate effect heat and mass transfer in natural convection flow from an isothermal sphere with chemical reaction. International Journal of Fluid Mechanics Research, 31(4), 319-331. http://dx.doi.org/10.1615/InterJFluidMechRes.v31.i4.20

Molla, M. M., Hossain, M. A., \& Yao, L. S. (2004). Natural convection flow along a vertical wavy surface with heat generation/absorption. International Journal of Thermal Science, 43, 157-163. http://dx.doi.org/10.1016/j.ijthermalsci.2003.04.001

Molla, M. M., Hossein, M. A., \& Paul, M. C. (2006). Natural Convection Flow from an Isothermal Horizontal Circural Cylinder in Presence of Heat Generation, International Journal of Engineering Science, 44, 949-958. http://dx.doi.org/10.1016/j.ijengsci.2006.05.002

Pop, I., Nazar, R., \& Amin, N. (2002). Free convection boundary layer on a horizontal circular cylinder wit constant heat flux in a micropolar fluid. International Journal Applied Mechanics \& Engineering, 7(2), 409-431.

Sparrow, E. M. L., \& Lee, L. (1976). Analysis of mixed convection about a circular cylinder. International Journal of Heat Mass Transfer, 19, 229-236. http://dx.doi.org/10.1016/0017-9310(76)90118-6

Sparrow, E. M., Husar, R. B., \& Goldstein, R. J. (1969). Observations and other characteristics of thermals. Journal of fluid Mech, 40, 593-610. http://dx.doi.org/10.1017/S0022112070000927

Takhar, H. S. (1968). Free convection from a flat plate. Journal of fluid Mech, 34, 81-89. http://dx.doi.org/10.1017/S0022112068001771

Vajravelu, K., \& Hadjinicolaou, A. (1993). Heat transfer in a viscous fluid over a stretching sheet with viscous dissipation and internal heat generation. International Communication Heat Mass Transfer, 20, 417-430. http://dx.doi.org/10.1016/0735-1933(93)90026-R

\section{Copyrights}

Copyright for this article is retained by the author(s), with first publication rights granted to the journal.

This is an open-access article distributed under the terms and conditions of the Creative Commons Attribution license (http://creativecommons.org/licenses/by/3.0/). 